\title{
Study on environmental indices and heat tolerance tests in hair sheep
}

\author{
L. Seixas ${ }^{1}$ - C. B. de Melo ${ }^{1}$ A. M. Menezes ${ }^{1}$ - A. F. Ramos $^{2}$ • G. R. Paludo ${ }^{1}$. \\ V. Peripolli ${ }^{1}$ - C. B. Tanure ${ }^{1}$ - J. B. G. Costa Junior ${ }^{1}$ - C. McManus ${ }^{1}$
}

Received: 23 May 2016 / Accepted: 31 March 2017 /Published online: 20 April 2017

(C) Springer Science+Business Media Dordrecht 2017

\begin{abstract}
The ability to predict the effects of climatic factors on animals and their adaptability is important for livestock production. The aim of the present study was to analyze whether existing indices are suitable for evaluating heat stress in Santa Ines and Morada Nova sheep, which are locally adapted hair sheep breeds from northeastern Brazil, and if the limits used to classify thermal stress are suitable for these breeds. Therefore, climatic, physiological, and physical parameters, as well as thermographic images, were collected in 26 sheep, $11 / 2$ years old, from two genetic groups (Santa Ines 12 males and 4 females; Morada Nov. 7 males and 3 females) for 3 days in both morning (4:00 a.m.) and afternoon (2:00 p.m.) with six repetitions, totalizing 156 repetitions. Statistical analysis included correlations and broken-line regressions. Iberia and Benezra indices were the tolerance tests that best correlated with the assessed parameters. High correlations between environmental indices and rectal or skin surface temperatures was observed, which indicates that these indices can be used for Santa Ines and Morada Nova sheep raised in central Brazil. However, some indicative values of thermal discomfort are different from the existing classification. Therefore, in order to classify appropriately, the model used needs to be carefully studied, because these classifying values can vary according to the
\end{abstract}

L. Seixas

luizasseixas@gmail.com

1 University of Brasilia (UnB), Graduate Program in Animal Sciences, Campus Darcy Ribeiro, Asa Norte, Brasília, DF, Brazil

2 Embrapa, Brasília, DF, Brazil species and model. Further research is necessary to establish indicators of thermal stress for sheep breeds raised in the region.

Keywords Adaptability $\cdot$ Heat tolerance $\cdot$ Iberia index $\cdot$ Small ruminant $\cdot$ Temperature-humidity index

\section{Introduction}

The climate of a particular region directly influences animal production. The central region of Brazil has the highest national growth rate in sheep production and is characterized by high levels of solar radiation and daily temperatures (including high daily amplitude), as well as long dry periods which can adversely affect animal production (Correa et al. 2012).

Heat is one of the main sources of stress which has an important impact on the production and reproduction of livestock species (Singh et al. 2016). In a tropical environment, heat stress can occur in the warm periods of the day when animals are not able to balance the amount of heat gained, resulting in an increased secretion of cortisol and behavioral changes, such as reduction in food intake and digestion, leading to production and reproductive performance losses (Correa et al. 2013). Also, physiological parameters such as respiratory rate and rectal and surface temperature tend to increase as environmental conditions become more stressful, with increasing air temperature (da Silva et al. 2017).

The ability to predict the response of animals allows for the improvement of management strategies that may be used to ameliorate heat load. Modeling heat load will allow planners to determine the feasibility of maintaining livestock in certain regions and locations (Gaughan et al. 
2011). Several indices using different variables have been developed to evaluate thermal stress (Bohmanova et al. 2007). The most common empirical model of heat load is the temperature-humidity index (THI), which is a combination of temperature effects and humidity on a single value associated with the level of heat load (Bohmanova et al. 2007; Gaughan et al. 2011) and has been used to assess thermal stress for many years (Gaughan et al. 2008).

Besides the environmental indices, heat tolerance tests, which take into account physiological parameters, are also used to determine adaptability. One of the earliest indices developed to evaluate thermal stress in animals was the Iberian heat tolerance test, which uses the rectal temperature as a variable (Gaughan et al. 2011). Later, Benezra (1954) developed a heat tolerance coefficient based on rectal temperature and respiratory rate (Gaughan et al. 2011). Other indices were also developed using rectal temperature, such as Rausschenbach-Yerokhin index (RY) which combined air and rectal temperatures in the model (Ferreira 2005) and Baccari Jr et al. (1986) that considered the difference in body temperature after solar exposure (Oliveira, E.M.B.O., 2012, unpublished PhD thesis Universidade de Brasília)..

Considering that the ability to predict environmental effects in animals and their ability to adapt is essential for livestock production and that heat indices were not developed specifically for sheep, the aim of the present study was to analyze if these indices are appropriate to evaluate heat stress in Santa Ines and Morada Nova sheep and if the limits used to classify thermal stress are suitable for these breeds.

\section{Material and methods}

The experiment was conducted over three consecutive days in the dry season (June) at Fazenda Sucupira located southwest of the city of Brasilia-DF $\left(15^{\circ} 52^{\prime}-15^{\circ} 56^{\prime} \mathrm{S}\right.$ and $48^{\circ} 00^{\prime}-48^{\circ} 02^{\prime} \mathrm{W}$ ), with altitudes ranging from 1050 to $1250 \mathrm{~m}$ and a total area of $1763 \mathrm{ha}$. The tropical climate is Aw, according to the Koppen classification, characterized by two distinct seasons, with rainy summers and dry winters (Silva et al. 2008).

\section{Environmental characterization}

The environment (Table 1) was characterized using the following measurements: Black globe temperature (TBG) in the sun and the shade, dry bulb temperature (TDB), and relative humidity $(\mathrm{RH})$ using a hygrometer, every $30 \mathrm{~min}$ from 3:30 a.m. to 4:00 p.m. The wet bulb temperature (TWB) and dew point (Td) were obtained using Grapsi (Digital Psychrometric Chart). The dry bulb temperature is the temperature of the air; the black globe temperature combines the effects of radiation, air temperature, and air
Table 1 Mean, standard deviation $( \pm \mathrm{SD})$, and minimum and maximum of climate measures during the experimental period in the morning (4:00 a.m.) and afternoon (2:00 p.m.)

\begin{tabular}{|c|c|c|c|c|}
\hline & Mean & $\pm \mathrm{SD}$ & Minimum & Maximum \\
\hline \multicolumn{5}{|l|}{ Morning } \\
\hline BGTsun & 16.28 & 0.45 & 15.5 & 17.5 \\
\hline BGTsh & 16.76 & 0.52 & 15.5 & 18.5 \\
\hline RH & 90.65 & 6.45 & 75 & 100 \\
\hline TDB & 15.40 & 0.47 & 14.6 & 16.6 \\
\hline TWB & 14.43 & 0.65 & 12.5 & 15.6 \\
\hline $\mathrm{Td}$ & 13.86 & 1.02 & 10.83 & 15.2 \\
\hline THI1 & 66.36 & 6.71 & 54.76 & 71.67 \\
\hline THI2 & 68.48 & 0.64 & 66.94 & 70.18 \\
\hline THI3 & 59.61 & 0.77 & 58.27 & 61.66 \\
\hline THI4 & 62.14 & 0.63 & 61.06 & 63.71 \\
\hline THI5 & 59.66 & 0.78 & 58.29 & 61.71 \\
\hline THI6 & 62.08 & 0.64 & 60.54 & 63.78 \\
\hline BGHI & 62.77 & 0.53 & 61.45 & 63.47 \\
\hline \multicolumn{5}{|l|}{ Afternoon } \\
\hline BGTsun & 35.65 & 9.70 & 18.5 & 49.5 \\
\hline BGTsh & 28.18 & 3.25 & 22.5 & 34 \\
\hline RH & 39.73 & 18.18 & 13 & 76 \\
\hline TDB & 32.59 & 6.47 & 22.8 & 43.2 \\
\hline TWB & 20.63 & 2.01 & 17.4 & 27.8 \\
\hline $\mathrm{Td}$ & 15.23 & 3.84 & 4.62 & 23.86 \\
\hline THI1 & 84.50 & 15.64 & 57.71 & 104.44 \\
\hline THI2 & 85.31 & 5.56 & 76.74 & 97.26 \\
\hline THI3 & 78.64 & 4.99 & 70.35 & 89.94 \\
\hline THI4 & 85.52 & 8.80 & 72.21 & 99.95 \\
\hline THI5 & 79.05 & 5.13 & 70.53 & 90.42 \\
\hline THI6 & 78.91 & 5.62 & 70.34 & 90.86 \\
\hline BGHI & 82.63 & 9.32 & 67.66 & 99.09 \\
\hline
\end{tabular}

Means were calculated from measurements every 30 min during the 3 days of experiment

BGTsun Black globe temperature in the sun $\left({ }^{\circ} \mathrm{C}\right), B G T$ sh Black globe temperature in the shadow $\left({ }^{\circ} \mathrm{C}\right), R H$ relative humidity $(\%), T D B$ dry bulb temperature $\left({ }^{\circ} \mathrm{C}\right), T W B$ wet bulb temperature $\left({ }^{\circ} \mathrm{C}\right), T d$ dew point $\left({ }^{\circ} \mathrm{C}\right)$, THI Temperature and Humidity Index, BGHI Black Globe-Humidity Index

velocity; air humidity influences the rate of evaporative heat loss from animals through both skin and lungs; wet bulb temperature is measured using a thermometer bulb covered with a saturated wick exposed to a stream of unsaturated air, and it depends on the air temperature, pressure, and humidity ratio; dew point is the lowest temperature to which the sample may be cooled without the condensation of some of the vapor (Kelly and Bond 1971).

Based on these data, the heat indices were calculated using the following equations:

1. Temperature-humidity index (THI) 


$$
\begin{aligned}
\text { THI } 1= & (0.55 \times \mathrm{TDB}+0.2 \times \mathrm{Td}) \times 1.8+32+17.5(\mathrm{NRC} 1971) \\
\mathrm{THI} 2= & {[0.4 \times(\mathrm{TDB}+\mathrm{TWB})] \times 1.8+32+15(\text { Thom } 1959) } \\
\mathrm{THI} 3= & (0.8 \times \mathrm{TDB})+[(\mathrm{RH} / 100) \times(\mathrm{TDB}-14.4)]+46.4(\text { Mader et al.2006 }) \\
\mathrm{THI} 4= & \mathrm{TDB}+(0.36 \times \mathrm{TDB})+41.2(\text { Johnson and Vanjonack } 1976) \\
\mathrm{THI} 5= & (1.8 \times \mathrm{TDB}+32)-[(0.55-0.0055 \times \mathrm{RH}) \times(1.8 \times \mathrm{TDB}-26.8)] \\
& (\mathrm{NRC} 1971) \\
\text { THI6 }= & (\mathrm{TDB}+\mathrm{TWB}) \times 0.72+40.6(\mathrm{NRC} 1971)
\end{aligned}
$$

\section{Black Globe-Humidity Index (BGHI)}

BGHI $=\mathrm{TBG}+0.36 \times \mathrm{Td}+41.5$ Buffington et al. 1981 Where

TDB dry bulb temperature $\left({ }^{\circ} \mathrm{C}\right)$

TWB wet bulb temperature $\left({ }^{\circ} \mathrm{C}\right)$

TBG black globe temperature $\left({ }^{\circ} \mathrm{C}\right)$

Td dew point $\left({ }^{\circ} \mathrm{C}\right)$

$\mathrm{RH}$ relative humidity (\%)

\section{Animal characterization}

Animal care procedures throughout the study followed protocols approved by the Ethics Committee for Animal Use (ECAU) at the University of Brasilia, number 44568/ 2009. The number of animals per breed was determined using the minimum number of replications formula in Kaps and Lamberson (2009) in accordance with ECAU regulations to detect differences between treatments at a level of 5 and $80 \%$ power of the test. The animals were raised on pasture and had ad libitum access to water throughout the experiment.

Twenty-six apparently healthy sheep, $11 / 2$ years old, from two genetic groups (Santa Ines 12 males and 4 females; Morada Nov. 7 males and 3 females), were used and data were collected twice a day, with a total of 156 observations. Santa Ines and Morada Nova sheep are locally adapted breeds from the northeast of Brazil, a region with hot climate and long drought periods.

\section{Physiological parameters evaluation}

Physiological parameters such as rectal temperature (RT, ${ }^{\circ} \mathrm{C}$ ), respiratory rate (RR, movements/min), and heart rate (HR, beats/min), as well as thermographic images, were collected for 3 days both in the morning (4:00 a.m.) and in the afternoon (2:00 p.m.) with six repetitions. RT was measured by inserting a digital thermometer $5 \mathrm{~cm}$ into the rectum against the rectum wall and the reading was taken after $1 \mathrm{~min}$. For recording RR, the flank movement was observed for $1 \mathrm{~min}$ and the HR was evaluated for $1 \mathrm{~min}$ using a stethoscope. The thermographs of eye, nose, foot, and left side of the animal were obtained using an infrared thermograph ThermaCAM® (FLIR Systems Inc., Wilsonville, OR, USA) using an emittance coefficient of 0.95 with distance of $1 \mathrm{~m}$ to measure the surface temperature of the animal. QuickReport ${ }^{\circledR}$ software (FLIR Systems Inc., Wilsonville, OR, USA) was used to analyze the thermographs. The area tool was used to obtain the eye, nose, foot (interdigital space at the back of the foot), neck, axilla, groin, rib, shoulder, and rump temperatures.

One day before taking the images, the following measurements were taken on each animal: skin thickness (ST) using an adipometer; coat samples $\left(1 \mathrm{~cm}^{2}\right)$ were collected, number of hair $(\mathrm{NH})$ was counted, and length of ten longest hair (HL) was measured, according to Paim et al. (2013). Skin (shaved shoulder area) and coat color were measured at the shoulder of the animal using BYKGardner Color-guide (Geretsried, Germany) based on the CIELAB, $\mathrm{L}^{*}, \mathrm{a}^{*}$ and $\mathrm{b}^{*}$ system, where $\mathrm{L}^{*}$ is the brightness, $a^{*}$ is the red content, and $b^{*}$ is the yellow content. Size measurements on the animals included shoulder height (SH), thoracic perimeter (TP), back (BKL) and body (BL) lengths, rump height $(\mathrm{RH})$, rump width (RW), and breast width (BW).

Heat tolerance test based on animal measures were calculated using the following equations:

1. Iberia or Rhoad test: a value closer to 100 indicates a better adapted animal

$$
\text { HTC }=100-18 \text { TR }-39.1 \text { Gaughan et al. } 2011
$$

where

HTC heat tolerance test

100 maximum efficiency to maintain body temperature at $39.1{ }^{\circ} \mathrm{C}$ (Reece et al. 2015)

18 constant

TR average rectal temperature $\left({ }^{\circ} \mathrm{C}\right)$ based on readings at 4:00 AM and 2:00 p.m.

$39.1{ }^{\circ} \mathrm{C}$ average rectal temperature considered normal for sheep (Reece et al. 2015)

2. Benezra test: the lower the value determined by the equation, the higher the degree of adaptability

$\mathrm{HT}=\mathrm{TR} / \mathrm{FR}+39.1 / 27$ Gaughan et al. 2011

where

HT heat tolerance index

TR rectal temperature in ${ }^{\circ} \mathrm{C}$

RR respiratory rate in breaths per minute

39.1 normal rectal temperature of sheep $\left({ }^{\circ} \mathrm{C}\right)$ (Reece et al. 2015)

27 normal respiration rate of sheep (breaths/min)

(Reece et al. 2015) 
3. Rauschenbach-Yerokhin (RY) cited by Ferreira (2005): a value closer to 100 indicates a better adapted animal

$\mathrm{HTI}=1.0 \mathrm{TDB}-20 d+60$

where

HTI heat tolerance index

TDB dry bulb temperature $\left({ }^{\circ} \mathrm{C}\right)$

$d$ difference between the rectal temperatures taken in the morning and afternoon

4. Bacarri heat tolerance index: a value closer to 10 indicates a better adapted animal (Baccari Jr et al. 1986)

$\mathrm{HTI}=10-(\mathrm{TR} 2-\mathrm{TR} 1)$

where

HTI heat tolerance index

10 maximum efficiency to maintain body temperature at equilibrium

TR2 average rectal temperature $\left({ }^{\circ} \mathrm{C}\right)$ at 2:00 p.m.

TR1 average rectal temperature $\left({ }^{\circ} \mathrm{C}\right)$ at 4:00 a.m.

\section{Statistical analysis}

Statistical analysis was performed using SAS version 9.3 (Statistical Analysis Institute, Cary, North Carolina). Correlations and "Broken-Line" regression were used to evaluate the relationship of environmental indices and heat tolerance tests with physiological, hematological, physical, and thermographic parameters. The results were considered significant at level of $5 \%$.

The regression model used in the broken line analysis was $y_{i}=\beta_{o}+\beta_{1} x_{1}+\beta_{2}\left(x_{i 1}-x\right)+\delta i$ where $\delta i=1$ if $x i 1>x$ and 0 if $x i 1<x$ where $y$ is the dependent variable, $x$ is the independent variable, and $\beta$ are regression components.

\section{Results}

High daily air temperature variation was seen during the experiment with high average temperature and low relative humidity in the afternoon (Table 1). High environmental indices were also observed in the afternoon. Correlations between environmental and physiological parameters were positives. Regarding heat tolerance tests, the Benezra coefficient was the only one that correlated significantly $(p \leq 0.05)$ with all the physiological parameters. The rectal temperature was negatively correlated with Iberia index and positively with the others (Table 2).

Negative correlations between the Iberia index and the morphometric measures and positive correlations between morphometric measures and rectal temperature, Benezra, Bacarri, and RY heat tolerance indices were observed. Rectal temperature and skin brightness were negatively correlated, as was Benezra index and hair brightness (Table 3).

In general, correlations between surface temperature and environmental indices were high and positive, with higher correlations between the temperature of the neck and THI3 and THI5. Regarding heat tolerance indices, the Benezra was the best correlated with surface temperatures. Surface temperatures were correlated negatively with the Iberia index and positively with RY and Benezra coefficient (Table 2).

The environmental indices were best correlated with the temperature of the neck and foot (Table 4). The inflection points between skin temperatures and environmental indices varied according to the equation used, with higher values for the THI1 and THI2 (Table 5).

\section{Discussion}

The THI is a good indicator of thermal stress (Koluman and Daskiran 2011). A classification established by the National Weather Service (USA) uses the Climate Security Index for Livestock (LCI 1970) associated with THI (Thom 1959) considering as normal a THI $\leq 74$, alert 75-78, danger 79-83, and emergency $\geq 84$ (Hahn et al. 2009).

The animals used in the experiment did not suffer heat stress during the morning ( THI $<74$ ), which can be attributed to the time (4:00 a.m.) when the data was collected. However, high THI (mean 85.52; maximum 99.95) was observed in the afternoon, reaching values classified as danger (79-83) and emergency (>84) (Hahn et al. 2009). Considering the climatic variations during the day, the maximum ambient temperature $\left(43.2^{\circ} \mathrm{C}\right.$ ) observed during the experiment was higher than the temperature of $25^{\circ} \mathrm{C}$, considered thermal comfort zone for Santa Ines sheep (Eustáquio Filho et al. 2011).

High amplitudes of thermal variation observed in the present work agrees with Paim et al. (2013), who reported that, due to the low temperature recorded during the night (12:00 a.m. and 4:00 a.m.) in the Midwest region, the animals suffered from cold stress at night and heat stress during the day. The animal's ability to respond to heat stress depends upon exposure to low temperatures during the night, and more specifically, the duration and intensity of this low temperature (Gaughan et al. 2008). Thus, according to Paim et al. (2013), low temperatures recorded during the night may have aided in the recovery of thermal stress suffered during the day.

The rectal temperature was best correlated with THI3 and THI5 (Table 2). As expected, correlations between Iberia 
Table 2 Correlations between environmental indices, heat tolerance indices, and physiological parameters for Morada Nova and Santa Ines hair sheep

\begin{tabular}{|c|c|c|c|c|c|c|c|c|c|c|c|c|}
\hline & Neck & Axilla & Groin & Rump & Rib & Shoulder & Eye & Nose & Foot & RT & HR & $\mathrm{RR}$ \\
\hline THI1 & 0.55 & 0.54 & 0.46 & 0.56 & 0.49 & 0.41 & 0.43 & 0.44 & 0.57 & 0.58 & 0.22 & 0.28 \\
\hline THI2 & 0.88 & 0.78 & 0.74 & 0.87 & 0.85 & 0.71 & 0.61 & 0.74 & 0.85 & 0.67 & 0.09 & 0.43 \\
\hline THI3 & 0.89 & 0.80 & 0.76 & 0.88 & 0.87 & 0.72 & 0.64 & 0.77 & 0.88 & 0.71 & 0.10 & 0.46 \\
\hline THI4 & 0.86 & 0.77 & 0.73 & 0.86 & 0.85 & 0.73 & 0.61 & 0.73 & 0.84 & 0.66 & 0.08 & 0.42 \\
\hline THI5 & 0.89 & 0.80 & 0.76 & 0.88 & 0.87 & 0.73 & 0.64 & 0.77 & 0.88 & 0.71 & 0.10 & 0.45 \\
\hline THI6 & 0.88 & 0.78 & 0.74 & 0.87 & 0.85 & 0.71 & 0.61 & 0.74 & 0.85 & 0.67 & 0.09 & 0.43 \\
\hline BGHI & 0.82 & 0.71 & 0.68 & 0.82 & 0.80 & 0.65 & 0.55 & 0.68 & 0.79 & 0.62 & 0.08 & 0.35 \\
\hline IBERIA & -0.03 & -0.23 & -0.17 & -0.06 & -0.11 & -0.09 & -0.17 & -0.04 & 0.02 & -0.44 & -0.09 & -0.15 \\
\hline RY & 0.15 & 0.13 & 0.20 & 0.17 & 0.18 & 0.34 & 0.14 & -0.02 & 0.03 & 0.22 & -0.02 & -0.07 \\
\hline BENE & 0.39 & 0.44 & 0.39 & 0.43 & 0.46 & 0.45 & 0.38 & 0.46 & 0.52 & 0.48 & 0.34 & 1.00 \\
\hline BACA & 0.16 & 0.10 & 0.18 & 0.13 & 0.14 & 0.30 & 0.09 & -0.03 & 0.04 & 0.20 & 0.03 & -0.03 \\
\hline
\end{tabular}

Numbers in bold are statistically significant $(p \leq 0.05)$

THI Temperature and Humidity Index, BGHI Black Globe-Humidity Index, $R Y$ Rauschenbach-Yerokhin, BENE Benezra coefficient, $B A C A$ Bacarri coefficient, $R T$ rectal temperature $\left({ }^{\circ} \mathrm{C}\right), H R$ heart rate (beats $\left./ \mathrm{min}\right), R R$ respiratory rate (movements $/ \mathrm{min}$ )

index and rectal temperature were negative, indicating that less adapted animals have higher rectal temperatures. Likewise, positive correlations between rectal temperature

Table 3 Correlations between heat tolerance indices and physical and physiological parameters for Morada Nova and Santa Ines hair sheep

\begin{tabular}{lrrrrrrr}
\hline & \multicolumn{1}{l}{ RT } & \multicolumn{1}{l}{ RR } & \multicolumn{1}{l}{ HR } & \multicolumn{1}{l}{ IBERIA } & \multicolumn{1}{l}{ RY } & BENE & BACA \\
\hline BL & $\mathbf{0 . 1 9}$ & 0.08 & -0.10 & $-\mathbf{0 . 4 2}$ & $\mathbf{0 . 1 6}$ & 0.15 & $\mathbf{0 . 1 9}$ \\
BKL & $\mathbf{0 . 2 2}$ & 0.09 & -0.13 & $-\mathbf{0 . 4 9}$ & $\mathbf{0 . 2 4}$ & 0.15 & $\mathbf{0 . 2 8}$ \\
SH & 0.13 & 0.06 & $-\mathbf{0 . 1 8}$ & $-\mathbf{0 . 3 0}$ & 0.13 & 0.01 & 0.08 \\
TP & $\mathbf{0 . 2 5}$ & $\mathbf{0 . 2 1}$ & 0.04 & $-\mathbf{0 . 5 4}$ & 0.11 & $\mathbf{0 . 1 8}$ & 0.11 \\
RW & $\mathbf{0 . 2 1}$ & 0.15 & -0.13 & $-\mathbf{0 . 4 8}$ & $\mathbf{0 . 2 4}$ & 0.04 & $\mathbf{0 . 2 3}$ \\
BW & $\mathbf{0 . 1 7}$ & $\mathbf{0 . 1 7}$ & 0.00 & $-\mathbf{0 . 3 9}$ & $\mathbf{0 . 3 0}$ & $\mathbf{0 . 1 4}$ & $\mathbf{0 . 3 2}$ \\
RW & 0.11 & $\mathbf{0 . 2 4}$ & -0.09 & $-\mathbf{0 . 2 2}$ & 0.15 & $\mathbf{0 . 2 5}$ & $\mathbf{0 . 2 2}$ \\
ST & $\mathbf{0 . 2 0}$ & 0.05 & -0.01 & $-\mathbf{0 . 4 4}$ & 0.14 & 0.08 & $\mathbf{0 . 1 6}$ \\
NH & 0.00 & 0.10 & -0.11 & 0.01 & -0.10 & 0.11 & -0.06 \\
HL & 0.14 & $\mathbf{0 . 2 7}$ & -0.02 & $-\mathbf{0 . 2 8}$ & 0.08 & $\mathbf{0 . 2 9}$ & 0.15 \\
L* & $-\mathbf{0 . 2 3}$ & -0.15 & 0.01 & $\mathbf{0 . 5 2}$ & -0.11 & -0.16 & -0.12 \\
a* & 0.12 & -0.06 & 0.10 & $-\mathbf{0 . 2 9}$ & 0.13 & -0.12 & 0.10 \\
b* & -0.04 & -0.08 & 0.14 & 0.07 & 0.08 & -0.13 & 0.07 \\
L2* & -0.07 & -0.17 & 0.07 & $\mathbf{0 . 1 7}$ & -0.09 & $-\mathbf{0 . 1 7}$ & -0.14 \\
a2* & -0.02 & -0.14 & 0.04 & 0.04 & -0.03 & -0.16 & -0.10 \\
b2* & -0.06 & $-\mathbf{0 . 1 7}$ & 0.11 & 0.12 & -0.06 & $-\mathbf{0 . 1 9}$ & -0.11 \\
\hline
\end{tabular}

Numbers in bold are statistically significant $(p \leq 0.05)$

$R Y$ Rauschenbach-Yerokhin, BENE Benezra coefficient, BACA Bacarri coefficient, $R T$ rectal temperature $\left({ }^{\circ} \mathrm{C}\right), H R$ heart rate (beats $\left./ \mathrm{min}\right), R R$ respiratory rate (movements/min), $B L$ body length $(\mathrm{cm}), B K L$ back length (cm), $\mathrm{SH}$ shoulder height (cm), TP thoracic perimeter (cm), RH Rump height $(\mathrm{cm}), B W$ breast width $(\mathrm{cm}), R W$ rump width $(\mathrm{cm}), S T$ skin thickness $(\mathrm{cm}), N H$ number of hairs, $H L$ hair length $(\mathrm{cm}), L * / L 2 *$ luminosity of skin and hair respectively, $a * / a 2 *$ red-green of skin and hair respectively, $b * / b 2 *$ yellow-blue of skin and hair respectively (CIELAB system) and Benezra index were observed, showing that lower rectal temperatures indicate better thermal adaptation. The perfect correlations between Benezra and respiratory rate may be due to the use of this parameter in the equation used to calculate the coefficient.

The indirect relation between Iberia index and the morphometric measures and direct relationship of these with Bacarri, RY, and Benezra indices indicate that larger animals have greater difficulty in thermal adaptation. Regarding the brightness of the skin and hair, greater brightness was associated with low rectal temperature and Benezra coefficient, indicating better adaptation, similar to that reported by McManus et al. (2011) and Batista et al. (2014), when comparing the adaptability of sheep with light and dark coat, who concluded that those with black hair were less tolerant to heat. Singh et al. (2016) also stated that a higher overall adaptability in Magra sheep in India might be due to the white and lustrous coat of this breed which reflects sunlight more than did other sheep breeds used in the study.

A study with West African Dwarf goats raised in Nigeria reported that exposure of the animals to high THI resulted in significant increase in skin temperature sites at the neck, ear, and thigh (Popoola et al. 2014). Daltro (2014) also observed a relationship between environmental indices and skin temperature, where low regression coefficient was reported between surface temperature and environmental index. However, in the present work, high regression coefficient was observed especially in relation to foot and neck temperatures, demonstrating that these were the best locations to measure skin temperature using thermographic cameras in the breeds used here. Strong correlations between foot temperature and heat production was noted in a previous study when comparing thermographic images of different body areas of 
Table 4 Broken-line regression between environmental indices and rectal and skin temperatures $\left({ }^{\circ} \mathrm{C}\right)$ for Morada Nova and Santa Ines hair sheep

\begin{tabular}{|c|c|c|c|c|c|}
\hline & $r$ & $r^{2}$ & SE & $\mathrm{CI}$ & \\
\hline \multicolumn{6}{|l|}{ THI1 } \\
\hline RT & 94.34 & 0.34 & 5.45 & 83.57 & 105.10 \\
\hline NECK & 94.22 & 0.30 & 6.65 & 81.05 & 107.40 \\
\hline AXILLA & - & - & - & - & - \\
\hline GROIN & - & - & - & - & - \\
\hline RUMP & - & - & - & - & - \\
\hline RIB & - & - & - & - & - \\
\hline SHOULDER & - & - & - & - & - \\
\hline EYE & - & - & - & - & - \\
\hline NOSE & - & - & - & - & - \\
\hline FOOT & 96.89 & 0.32 & 7.78 & 81.45 & 112.30 \\
\hline \multicolumn{6}{|l|}{ THI2 } \\
\hline RT & 80.26 & 0.45 & 1.57 & 77.13 & 83.95 \\
\hline NECK & 83.58 & 0.82 & 1.01 & 81.58 & 85.58 \\
\hline AXILLA & 81.97 & 0.71 & 1.18 & 79.65 & 84.29 \\
\hline GROIN & - & - & - & - & - \\
\hline RUMP & 75.19 & 0.76 & 2.32 & 70.60 & 79.77 \\
\hline RIB & 84.01 & 0.73 & 1.05 & 81.93 & 86.10 \\
\hline SHOULDER & - & - & - & - & - \\
\hline EYE & 81.87 & 0.45 & 2.11 & 77.70 & 86.05 \\
\hline NOSE & - & - & - & - & - \\
\hline FOOT & - & - & - & - & - \\
\hline \multicolumn{6}{|l|}{ THI3 } \\
\hline RT & 63.60 & 0.50 & 1.07 & 61.48 & 65.71 \\
\hline NECK & - & - & - & - & - \\
\hline AXILLA & 67.32 & 0.69 & 3.02 & 61.36 & 73.28 \\
\hline GROIN & 67.35 & 0.60 & 3.71 & 60.01 & 74.68 \\
\hline RUMP & 68.30 & 0.76 & 3.25 & 61.87 & 74.73 \\
\hline RIB & 78.25 & 0.77 & 1.23 & 75.81 & 80.69 \\
\hline SHOULDER & 67.13 & 0.49 & 4.43 & 58.38 & 75.88 \\
\hline EYE & 65.28 & 0.45 & 2.77 & 59.81 & 70.75 \\
\hline NOSE & - & - & - & - & - \\
\hline FOOT & - & - & - & - & - \\
\hline \multicolumn{6}{|l|}{ THI4 } \\
\hline RT & 65.39 & 0.44 & 0.86 & 63.69 & 67.08 \\
\hline NECK & 81.32 & 0.82 & 1.28 & 78.79 & 83.85 \\
\hline AXILLA & 68.80 & 0.69 & 2.72 & 63.42 & 74.17 \\
\hline GROIN & 68.56 & 0.60 & 3.09 & 62.46 & 74.66 \\
\hline RUMP & 69.73 & 0.75 & 3.01 & 63.79 & 75.67 \\
\hline RIB & 82.27 & 0.77 & 1.46 & 79.38 & 85.16 \\
\hline SHOULDER & 68.17 & 0.52 & 3.44 & 61.37 & 74.98 \\
\hline EYE & 66.71 & 0.37 & 2.17 & 62.42 & 70.99 \\
\hline NOSE & - & - & - & - & - \\
\hline FOOT & 76.16 & 0.84 & 2.27 & 71.65 & 80.67 \\
\hline \multicolumn{6}{|l|}{ THI5 } \\
\hline RT & 63.60 & 0.50 & 1.03 & 61.56 & 65.64 \\
\hline NECK & - & - & - & - & - \\
\hline
\end{tabular}

Table 4 (continued)

\begin{tabular}{|c|c|c|c|c|c|}
\hline & $r$ & $r^{2}$ & $\mathrm{SE}$ & CI & \\
\hline AXILLA & 67.45 & 0.69 & 3.03 & 61.46 & 73.43 \\
\hline GROIN & 67.36 & 0.60 & 3.62 & 60.21 & 74.50 \\
\hline RUMP & 68.70 & 0.76 & 3.47 & 61.84 & 75.55 \\
\hline RIB & 78.63 & 0.75 & 1.26 & 76.15 & 81.11 \\
\hline SHOULDER & 66.85 & 0.52 & 3.99 & 58.97 & 74.73 \\
\hline EYE & 65.21 & 0.45 & 2.61 & 60.05 & 70.37 \\
\hline NOSE & - & - & - & - & - \\
\hline FOOT & 73.74 & 0.84 & 2.31 & 69.16 & 78.31 \\
\hline \multicolumn{6}{|l|}{ THI6 } \\
\hline RT & 73.86 & 0.45 & 1.59 & 70.73 & 76.99 \\
\hline NECK & - & - & - & - & - \\
\hline AXILLA & 75.57 & 0.71 & 1.18 & 73.25 & 77.89 \\
\hline GROIN & 75.79 & 0.62 & 1.47 & 72.88 & 78.69 \\
\hline RUMP & 68.79 & 0.76 & 2.32 & 64.20 & 73.37 \\
\hline RIB & 77.61 & 0.77 & 1.05 & 75.53 & 79.70 \\
\hline SHOULDER & - & - & - & - & - \\
\hline EYE & - & - & - & - & - \\
\hline NOSE & - & - & - & - & - \\
\hline FOOT & - & - & - & - & - \\
\hline \multicolumn{6}{|l|}{ BGHI } \\
\hline RT & 74.25 & 0.39 & 1.56 & 71.16 & 77.35 \\
\hline NECK & 76.24 & 0.83 & 0.87 & 74.52 & 77.96 \\
\hline AXILLA & 70.84 & 0.69 & 1.60 & 67.68 & 74.01 \\
\hline GROIN & 76.13 & 0.61 & 1.43 & 73.30 & 78.96 \\
\hline RUMP & 70.90 & 0.77 & 1.32 & 68.29 & 73.51 \\
\hline RIB & 77.26 & 0.76 & 1.04 & 75.21 & 79.30 \\
\hline SHOULDER & 76.30 & 0.53 & 1.61 & 73.12 & 79.48 \\
\hline EYE & 75.62 & 0.44 & 2.25 & 71.17 & 80.07 \\
\hline NOSE & 71.08 & 0.65 & 2.69 & 65.77 & 76.40 \\
\hline FOOT & - & - & - & - & - \\
\hline
\end{tabular}

$r$ inflection point, $r^{2}$ regression coefficient, $S E$ standard error, $C I 95 \%$ confidence interval, THI Temperature and humidity index, BGHI Black Globe-Humidity Index, $R T$ rectal temperature $\left({ }^{\circ} \mathrm{C}\right)$

dairy cattle suggesting that this could be the best location to infer heat production using thermographic temperatures (Montanholi et al. 2008). However, in sheep, despite the high regression coefficient between the foot and THI, this may not be the best location to capture thermographic images due to the small size of the foot and difficulty in obtaining a clear isolated image.

There is no classification of THI and BGHI developed specifically for sheep. In the present work, considering the inflection point, on average, BGHI of 74 can be considered as a critical value for Santa Ines and Morada Nova sheep, which is in agreement with the classification established by the National Weather Service (USA) (Hahn et al. 2009). However, Andrade (2006, unpublished MSc thesis, Federal University of Campina Grande) did not consider BGHI above 
Table 5 Broken-line regression between the mean skin temperatures and environmental indices for Morada Nova and Santa Ines hair sheep

\begin{tabular}{lllr}
\hline & r & CI & \\
\hline THI1 & 95.55 & 81.45 & 109.85 \\
THI2 & 81.32 & 72.29 & 84.36 \\
THI3 & 68.94 & 62.87 & 75.00 \\
THI4 & 72.71 & 67.91 & 77.52 \\
THI5 & 69.70 & 63.98 & 75.43 \\
THI6 & 74.44 & 71.46 & 77.41 \\
BGHI & 74.30 & 71.13 & 77.46 \\
\hline
\end{tabular}

$r$ inflection point, $C I 95 \%$ confidence interval, THI Temperature and humidity index, $B G H I$ Black Globe-Humidity Index

84 as thermal discomfort situation for Santa Ines lambs in the semiarid region. As for Cezar et al. (2004), a BGHI of 82.4 can be classified as at risk for heat stress for Santa Ines and Dorper sheep and their crossbreeds.

Regarding THI, inflection points between surface temperature and environmental indices suggest different classification values of heat stress for Santa Ines and Morada Nova sheep. The THI2 (Thom 1959) was the closest to this classification, as expected, because the equation used to determine these values was also based on Thom (1959). Thus, this THI equation can be used to determine the critical situation of heat stress for sheep. However, in other THIs, with the exception of THI1, the inflection point was lower than the limit set as critical. This demonstrates that depending on the model used, a THI less than 74 (which according to the classification used for human and cattle is considered a thermal comfort zone) can be an indicator of thermal discomfort for hair sheep. In bioclimatic zoning for sheep on Pernambuco, Brazil, a THI lower than 74 (72.8) was also considered as a critical limit where respiratory rate tends to increase and sheep begin to feel thermal discomfort (Mendes et al. 2014).

High correlations between environmental indices with rectal and skin temperatures demonstrates that these indices are good tools to evaluate thermal comfort of Santa Ines and Morada Nova sheep raised in central Brazil. However, in order to classify these appropriately, the model used needs to be carefully studied, because classifying values can vary according to the species and model. Regarding the heat tolerance tests, Iberia and Benezra indices seem to be best correlated with the parameters studied.

Santa Ines and Morada Nova are locally adapted hair breeds which are generally raised in areas with high THI and air temperatures, lower precipitation, and relative humidity (McManus et al. 2014), so it is important to establish which values are indicative of thermal discomfort in order to adopt measures to mitigate heat stress and not compromise the production performance of the breeds. Therefore, further research is necessary to establish indicators of thermal stress for sheep breeds raised in the region.
Acknowledgments The authors thank CAPES and CNPq for financing and scholarships.

\section{Compliance with ethical standards}

Conflict of interest The authors declare that they have no competing interests.

Ethical statement Animal care procedures throughout the study followed protocols approved by the Ethics Committee for Animal Use (ECAU) at the University of Brasilia, number 44568/2009.

\section{References}

Baccari Jr, F., Polastre, R., Fré, C.A. and Assis, P.S., 1986. Um novo índice de tolerância ao calor para bubalinos: correlação com o ganho de peso, Proceedings of the Reunião Anual da Sociedade de Zootecnia, SBZ, Campo Grande, 316

Batista, N., Souza, B., Roberto, J., Araújo, R., Ribeiro, T., Silva, R. and Oliveira, G., 2014. Tolerância ao calor em ovinos de pelames claro e escuro submetidos ao estresse térmico, Journal of Animal Behaviour Biometeorology, 2, 102-108

Benezra, M., 1954. A new index for measuring the adaptability of cattle to tropical conditions, Journal of Animal Science, 13, 1015-1015

Bohmanova, J., Misztal, I. and Cole, J., 2007. Temperature-humidity indices as indicators of milk production losses due to heat stress, Journal of Dairy Science, 90, 1947-1956

Buffington, D., Collazo-Arocho, A., Canton, G. and Pitt, D., 1981. Black globe-humidity index (BGHI) as comfort equation for dairy cows, Transactions of the American Society of Agricultural Engineers, 24, $711-714$

Cezar, M.F., Souza, B., Souza, W., Pimenta Filho, E., Tavares, G.D.P. and Medeiros, G.X., 2004. Avaliação de parâmetros fisiológicos de ovinos Dorper, Santa Inês e seus mestiços perante condições climáticas do trópico semi-árido nordestino, Ciência e Agrotecnologia, 28, 614-620

Correa, M.P.C., Cardoso, M.T., Castanheira, M., Landim, A.V., Dallago, B.S.L., Louvandini, H. and McManus, C., 2012. Heat tolerance in three genetic groups of lambs in central Brazil, Small Ruminant Research, 104, 70-77

Correa, M. P. C., Dallago, B.S.L., Paiva, S. R., Canozzi, M. E. A., Louvandini, H., Barcellos, J. J. and McManus, C. M., 2013. Multivariate analysis of heat tolerance characteristics in Santa Inês and crossbred lambs in the Federal District of Brazil, Tropical Animal Health and Production, 45, 1407-1414

da Silva, W.E., Leite, J.H.G.M., de Sousa, J.E.R., Costa, W.P., Silva, W.S.T., Guilhermino, M.M., Asensio, L.A.B. and Façanha, D.A.E., 2017. Daily rhythmicity of the thermoregulatory responses of locally adapted Brazilian sheep in a semiarid environment. International Journal of Biometeorology, 1-11.

Daltro, D.S., 2014. Uso da termografia infravermelha para avaliar a tolerancia ao calor em bovinos de leite submetidos ao estresse termico, (unpublished MSc thesis, Federal University of Rio Grande do Sul).

Eustáquio Filho, A., Teodoro, S.M., Chaves, M.A., Santos, P.E.F., Silva, M.W.R., Murta, R.M., Carvalho, G.G.P. and Souza, L.E.B., 2011. Zona de conforto térmico de ovinos da raça Santa Inês com base nas repostas fisiológicas, Revista Brasileira de Zootecnia, 40, 19071814

Ferreira, R.A., 2005. Maior produção com melhor ambiente para aves, suínos e bovinos, (Aprenda Fácil, Viçosa)

Gaughan, J.B., Mader, T.L., Holt, S.M. and Lisle, A., 2008. A new heat load index for feedlot cattle, Jounal of Animal Science, 86, 226-234 
Gaughan, J., Mader, T. and Gebremedhin, K., 2011. Rethinking heat index tools for livestock, Environmental Physiology of Livestock, (John Wiley \& Sons, West Sussex)

Hahn, G.L., Gaughan, J.B., Mader, T.L. and Eigenberg, R.A., 2009. Thermal indices and their applications for livestock environments. Livestock energetics and thermal environment management, (American Society of Agricultural and Biological Engineers, St. Joseph)

Johnson, H. and Vanjonack, W., 1976. Effects of environmental and other stressors on blood hormone patterns in lactating animals, Journal of Dairy Science, 59, 1603-1617

Kaps, M. and Lamberson, W.R., 2009. Biostatistics for animal science: an introductory text, (CABI, Cambridge)

Kelly, C.F. and Bond, T.E., 1971. Bioclimatic factors and their measurement, a guide to environmental research on animals (National Academy of Sciences, Washington DC)

Koluman, N. and Daskiran, I., 2011. Effects of ventilation of the sheep house on heat stress, growth and thyroid hormones of lambs, Tropical Animal Health and Production, 43, 1123-1127

LCI, 1970. Patterns of transit losses, (Livestock Conservation, Omaha)

Mader, T.L., Davis, M. and Brown-Brandl, T., 2006. Environmental factors influencing heat stress in feedlot cattle, Journal of Animal Science, 84, 712-719

McManus, C., Louvandini, H., Gugel, R., Sasaki, L.C., Bianchini, E., Bernal, F.E., Paiva, S.R. and Paim, T.P., 2011. Skin and coat traits in sheep in Brazil and their relation with heat tolerance, Tropical Animal Health and Production, 43, 121-126

McManus, C., Hermuche, P., Paiva, S.R., Moraes, J.C.F., de Melo, C.B., and Mendes, C., 2014. Geographical distribution of sheep breeds in brazil and their relationship with climatic and environmental factors as risk classificationfor conservation, Brazilian Journal of Science and Technology, 1, 1-15

Mendes, A.M. P., Azevedo M., Lopes P.M.O. and Moura G.B.A., 2014. Zoneamento bioclimático para a raça ovina Dorper no Estado de Pernambuco, Pesquisa Agropecuária Brasileira, 49, 986-993

Montanholi, Y.R., Odongo, N.E., Swanson, K.C., Schenkel, F.S., McBride, B.W. and Miller, S.P., 2008. Application of infrared thermography as an indicator of heat and methane production and its use in the study of skin temperature in response to physiological events in dairy cattle (Bos taurus), Journal of Thermal Biology, 33, 468-475

NRC, 1971. A guide to environmental research on animals, (National Academy of Sciences, Washington DC)

Paim, T. P., Borges, B.O., Lima, P. M.T., Gomes, E.F., Dallago, B.S.L., Fadel, R., de Menezes, A.M., Louvandini, H., Canozzi, M.E.A., Barcellos, J.O.J., and McManus C., 2013. Thermographic evaluation of climatic conditions on lambs from different genetic groups, International journal of biometeorology, 57, 59-66

Popoola, M.A., Sakab, A.A., Olaniyia, T.A., Yahayaa, M.O. and Adebisic, G.L., 2014. Influence of temperature humidity index on skin temperature of West African Dwarf goats raised in Nigeria, Agricultural Advances, 3, 28-32

Reece, W.O., Erickson, H.H., Goff, J.P., and Uemura, E.E., 2015. Dukes' physiology of domestic animals, (Wiley, New York)

Silva, F.D., Assad, E. and Evangelista, B., 2008. Caracterização climática do bioma Cerrado, Cerrado: ecologia e flora 1, 69-88

Singh K.M., Singh, S., Ganguly, I., Ganguly, A., Nachiappan, R.K., Chopra, A., and Narula, H.K., 2016. Evaluation of Indian sheep breeds of arid zone under heat stresscondition, Small Ruminant Research, 141, 113-117

Thom, E.C., 1959. The discomfort index, Weatherwise 12, 57-59 